\title{
Total anomalous pulmonary venous connection: Results of surgical repair of 100 patients at a single institution
}

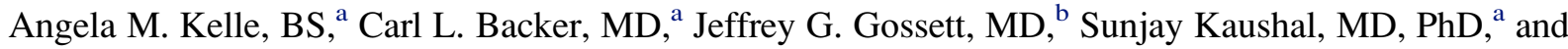 \\ Constantine Mavroudis, $\mathrm{MD}^{\mathrm{c}}$
}

Objective: Surgical repair of total anomalous pulmonary venous connection is associated with significant mortality and morbidity, especially in patients with single-ventricle physiology. This study analyzes total anomalous pulmonary venous connection surgical repair results at one institution to identify trends and indicators of positive outcome.

\begin{abstract}
Methods: Our cardiac surgery database identified 100 patients undergoing surgical repair of total anomalous pulmonary venous connection (1990-2008): supracardiac (52), cardiac (15), infracardiac (23), and mixed (10). The median age at repair was 14.6 days (range, $0-4$ years), and the median weight was $3.5 \mathrm{~kg}$ (range, $1.3-15 \mathrm{~kg}$ ). Patients were divided into 2 groups: biventricular $(n=83)$ or single-ventricle $(n=17)$ physiology. All but 1 of the patients with single-ventricle physiology had heterotaxy syndrome (94\%), and 13 of 17 patients had supracardiac anatomy.
\end{abstract}

Results: There were 12 operative deaths (4 in the biventricular group [5\%] and 8 in the single-ventricle group [47\%], $P<.01$ ) and 9 late deaths (6 in the biventricular group [7\%] and 3 in the single-ventricle group [18\%], $P<.05)$. Death by total anomalous pulmonary venous connection type was supracardiac $(12 / 52 ; 23.1 \%)$, cardiac $(1 / 15 ; 6.7 \%)$, infracardiac $(3 / 23 ; 13.0 \%)$, and mixed $(5 / 10 ; 50 \%)$. Pulmonary venous obstruction was present in 22 patients in the biventricular group (27\%) and in 7 patients in the single-ventricle group $(41 \% ; P=.25)$. Mortality was 9 of $29(31 \%)$ in those with pulmonary venous obstruction and 12 of $71(17 \%)$ in those with nonpulmonary venous obstruction $(P=.23)$. Deep hypothermic circulatory arrest was used in 38 patients (27 in the biventricular group, $32.5 \% ; 11$ in the single-ventricle group, $64.7 \%$ ). Mean deep hypothermic circulatory arrest time was $31.4 \pm$ 10.7 minutes ( $P=$ not significant between groups). Median postoperative length of stay was 11 days (range, $0-281$ days). Nineteen patients required reoperation for pulmonary venous stenosis (14 in the biventricular group and 5 in the single-ventricle group. $P=.045$ ); the median time to reoperation was 104 days (range, 4-753 days).

Conclusion: Patients with total anomalous pulmonary venous connection with biventricular anatomy have good outcomes. Patients with single-ventricle anatomy have higher mortality and increased risk for pulmonary vein stenosis requiring reoperation. Mortality is highest in patients with mixed-type total anomalous pulmonary venous connection. (J Thorac Cardiovasc Surg 2010;139:1387-94)

\section{Supplemental material is available online.}

Total anomalous pulmonary venous connection (TAPVC) is a rare cardiac anomaly, occurring in only $1 \%$ to $3 \%$ of

\footnotetext{
From the Division of Cardiovascular-Thoracic Surgery, Department of Surgery, ${ }^{\text {a }}$ and the Division of Cardiology, Department of Pediatrics, ${ }^{b}$ Northwestern University Feinberg School of Medicine, Children's Memorial Hospital, Chicago, Ill; and the Cleveland Clinic Foundation, ${ }^{c}$ Cleveland Clinic Lerner School of Medicine, Case Western Reserve University, Cleveland, Ohio.

Disclosures: None.

Presented at the 35th annual meeting of the Western Thoracic Surgical Association, June 27, 2009, Banff, AB, Canada.

Received for publication June 26, 2009; revisions received Dec 8, 2009; accepted for publication Feb 8, 2010; available ahead of print April 15, 2010.

Address for reprints: Carl L. Backer, MD, Division of Cardiovascular-Thoracic Surgery, Children's Memorial Hospital, 2300 Children's Plaza, mc 22, Chicago, IL 60614 (E-mail: cbacker@childrensmemorial.org).

0022-5223/\$36.00

Copyright (c) 2010 Published by Elsevier Inc. on behalf of The American Association for Thoracic Surgery

doi:10.1016/j.jtcvs.2010.02.024
}

children born with congenital heart defects. ${ }^{1,2}$ The lesion is characterized by an abnormal drainage of the pulmonary veins to systemic venous circulation through a persistent embryologic connection. Without surgical correction, TAPVC leads to greater than $78 \%$ mortality during the first year. ${ }^{3}$ Mortality rates after surgical correction of TAPVC have improved with advances in surgical technique and medical management; however, repair does remain a challenge with early mortality reported in the literature at rates ranging from less than $10 \%$ to $50 \%{ }^{1,4,5}$ Not surprisingly, isolated TAPVC in a patient with biventricular (BV) anatomy, without severe concomitant cardiac defects, is associated with the best prognosis. ${ }^{1,4}$ Infants with single-ventricle (SV) physiology and infants with heterotaxy syndrome are particularly high-risk groups. ${ }^{1,4}$ Reports of morbidity after TAPVC surgery are highly variable and include arrhythmias, pulmonary hypertension, and residual pulmonary venous obstruction. ${ }^{4,6}$ Pulmonary vein obstruction, either within the pulmonary veins or at the anastomotic site, remains an issue in $10 \%$ to $20 \%$ of most series. In light of the variability in 


$$
\begin{aligned}
& \text { Abbreviations and Acronyms } \\
& \text { BV }=\text { biventricular } \\
& \text { CPB }=\text { cardiopulmonary bypass } \\
& \text { DHCA }=\text { deep hypothermic circulatory arrest } \\
& \text { PDS }=\text { polydioxanone } \\
& \text { SV }=\text { single ventricle } \\
& \text { TAPVC }=\text { total anomalous pulmonary venous } \\
& \text { connection }
\end{aligned}
$$

the literature, a retrospective review of all patients undergoing repair of TAPVC since 1990 at Children's Memorial Hospital was performed. The purpose of the study was to determine the outcomes after repair and identify trends and possible predictors of the outcomes.

\section{PATIENTS AND METHODS}

The institutional review board at Children's Memorial Hospital, Chicago, Illinois, approved this retrospective study and granted a waiver of informed consent on February 4, 2007. We identified patients via the computerized database for cardiac surgical patients at Children's Memorial Hospital, which was established in 1990 . Hospital and clinic charts were reviewed to confirm entries; operative notes, catheterization reports, and echocardiograms were reviewed.

Potential predictors of operative outcome that were evaluated included BV versus functional SV anatomy, heterotaxy versus non-heterotaxy, TAPVC anatomic type, preoperative pulmonary venous obstruction, use of deep hypothermic circulatory arrest (DHCA) versus continuous cardiopulmonary bypass (CPB), and year/era of surgical repair. The primary outcome measures evaluated were operative and late mortality and reoperation for pulmonary venous stenosis, as well as time-to-mortality and time to reoperation. Preoperative pulmonary venous obstruction was defined as intrinsic or extrinsic narrowing of the anomalous pulmonary venous channel or obstruction at the interatrial septum. ${ }^{7}$ Operative mortality was defined as death within 30 days of an operation or within the primary hospitalization. ${ }^{8}$

Long-term survival analysis was completed using date of death or date of last follow-up at Children's Memorial Hospital. Total elapsed time since surgery was calculated until the end of study (December 21, 2008). Follow-up echocardiogram data were analyzed in patients for whom echocardiograms were available more than 1 month after their repair. Data from the most recent echocardiogram were reviewed by a single echocardiographer. Every effort was made to obtain the original study tape for review; in cases in which the tape was not available, the echocardiography report was reviewed. Maximal gradient was measured at the level of the pulmonary venous confluence to the left atrium.

\section{Patient Demographics}

Between the years 1990 and 2008, 100 patients underwent repair of TAPVC at Children's Memorial Hospital. All patients who underwent TAPVC repair during this time period were included in the analysis. Patient characteristics are summarized in Table 1 . Of the 17 patients with SV anatomy, $16(94 \%)$ had heterotaxy syndrome. Two of the 83 patients with BV anatomy had heterotaxy syndrome $(2.4 \%)$. All patients with heterotaxy had right-sided isomerism with asplenia. Mean CPB time differed significantly between groups: $86.2 \pm 31.0$ minutes in the $\mathrm{BV}$ group versus $139.4 \pm 53.3$ minutes in the $\mathrm{SV}$ group $(P<.01)$. Mean aortic crossclamp time was similar between groups: $43.9 \pm 22.4$ minutes in the $\mathrm{BV}$ group versus $37.3 \pm 26.8$ minutes in the SV group ( $P=$ not significant). DHCA was used in 27 patients in the BV group (32.5\%) and in 11 patients in the SV group (64.7\%); there was no difference in mean DHCA time between groups ( $P=$ not significant).

\section{Surgical Technique}

Patients were repaired with either continuous $\mathrm{CPB}$ and mild hypothermia $\left(28^{\circ} \mathrm{C}\right)$ or DHCA $\left(18^{\circ} \mathrm{C}\right)$. Crossclamp with cold-blood cardioplegia was used for myocardial protection in all cases. The selection of continuous CPB versus DHCA was primarily based on the complexity of the repair with a tendency toward more frequent use of DHCA for the more complex repairs. The vertical vein was ligated in all cases just before opening the common pulmonary vein. For the patient with normal situs, the heart was retracted out of the left chest toward the patient's right shoulder (Figure E1). An incision was made in the anterior surface of the common pulmonary vein in the posterior pericardium. A mirror counter incision was made in the posterior aspect of the left atrial appendage. Through this opening in the left atrium, the atrial communication was visualized and closed with Prolene. An anastomosis was created between the orifice in the posterior aspect of the left atrium and the common pulmonary vein (Figure E2). The suture material for this technique was 6.0 or 7.0 Prolene $(n=80)$ or polydioxanone (PDS) suture $(\mathrm{n}=8)$ (not described, $\mathrm{n}=12)$. Nitric oxide was used frequently in the more recent era (past 10 years). In elective or semi-urgent cases, transesophageal echocardiography was used selectively and carefully in the operating room with the realization that compression of the common pulmonary vein and postoperative confluence was a potential problem. One patient had a cardiac arrest on the induction of anesthesia (no transesophageal echocardiogram probe used) and underwent cardiopulmonary resuscitation while being cannulated. That patient survived.

\section{Statistical Analysis}

CPB time, aortic crossclamp time, and DHCA time were compared using $t$ tests. For BV versus SV groups, the rates of operative death, late death, and reoperation were compared using Fisher's exact test. In Tables 2 and 3, patient variables possibly associated with time to death or time to reoperation were examined using Cox proportional hazard modeling. In Figure 1, Kaplan-Meier curves for BV and SV time to death are presented. Analysis was performed using SAS 9.1 (SAS Institute, Inc, Cary, NC).

\section{RESULTS \\ Operative and Late Mortality}

There were 12 operative deaths $(12 / 100,12 \% ; 4$ in the BV group [5\%] vs 8 in the SV group [47\%], $P<.01)$ and 9 late deaths $(9 / 88,10 \% ; 6$ in the BV group [7\%] vs 3 in the SV group $[18 \%], P<.05)$. Death by TAPVC type was supracardiac $(12 / 52 ; 23.1 \%)$, cardiac $(1 / 15 ; 6.7 \%)$, infracardiac $(3 / 23 ; 13.0 \%)$, and mixed $(5 / 10 ; 50 \%)$. Preoperative pulmonary venous obstruction was present in 9 of the patients who died $(9 / 21,43 \%)$; therefore, of the 29 patients who had preoperative pulmonary venous obstruction, mortality was 9 of $29(31 \%)$ versus 12 of 71 patients $(17 \%)$ with unobstructed veins $(P=.23)$. Time to death ranged from 0 days to 3.8 years; 17 of 21 deaths ( $81 \%$ of deaths) occurred within 4 months after surgery. These results are summarized in Figure E3.

Patient variables possibly associated with time to mortality are summarized in Table 2. Functional SV anatomy, heterotaxy syndrome, mixed-type TAPVC, CPB time, and use of DHCA were significantly associated with earlier time to mortality, and pulmonary atresia trended toward significance. Higher weight at surgery was found to have 
TABLE 1. Characteristics of patients who underwent TAPVC surgical repair at Children's Memorial Hospital (1990-2008)

\begin{tabular}{|c|c|c|c|}
\hline Patient characteristics & $\begin{array}{c}\text { Value } \\
\text { All patients }\end{array}$ & $\begin{array}{c}\text { Value Patients } \\
\text { with BV anatomy }\end{array}$ & $\begin{array}{c}\text { Value Patients } \\
\text { with } S V \text { anatomy }\end{array}$ \\
\hline Age at time of operation, median (range) & $\begin{array}{l}14.6 \mathrm{~d} \\
(0-4 \mathrm{y})\end{array}$ & $\begin{array}{l}14.6 \mathrm{~d} \\
(0-1.7 \mathrm{y})\end{array}$ & $\begin{array}{l}14.6 \mathrm{~d} \\
(0-4 \mathrm{y})\end{array}$ \\
\hline Weight, median (range) & $\begin{array}{l}3.5 \mathrm{~kg} \\
(1.3-15 \mathrm{~kg})\end{array}$ & $\begin{array}{l}3.5 \mathrm{~kg} \\
(1.3-10 \mathrm{~kg})\end{array}$ & $\begin{array}{l}3.2 \mathrm{~kg} \\
(1.9-15 \mathrm{~kg})\end{array}$ \\
\hline Height, median (range) & $\begin{array}{c}52 \mathrm{~cm} \\
(40.5-150 \mathrm{~cm})\end{array}$ & $\begin{array}{c}52 \mathrm{~cm} \\
(40.5-150 \mathrm{~cm})\end{array}$ & $\begin{array}{c}57 \mathrm{~cm} \\
(45-112 \mathrm{~cm})\end{array}$ \\
\hline \multicolumn{4}{|l|}{ Gender } \\
\hline Female & 42 & 31 & 11 \\
\hline Male & 58 & 52 & 6 \\
\hline \multicolumn{4}{|l|}{ TAPVC anatomic type } \\
\hline Supracardiac (type 1) & 52 & 39 & 13 \\
\hline Cardiac (type 2) & 15 & 15 & 0 \\
\hline Infracardiac (type 3) & 23 & 21 & 2 \\
\hline Mixed (type 4) & 10 & 8 & 2 \\
\hline \multicolumn{4}{|l|}{ Ventricular anatomy and diagnoses } \\
\hline SV & 17 & - & 17 \\
\hline Heterotaxy & 18 & 2 & 16 \\
\hline Pulmonary atresia & 8 & 1 & 7 \\
\hline Pulmonary coarctation & 7 & 1 & 6 \\
\hline Preoperative PV obstruction & 29 & 22 & 7 \\
\hline \multicolumn{4}{|l|}{ Previous cardiac operations } \\
\hline Norwood procedure & 1 & 0 & 1 \\
\hline PDA ligation & 3 & 1 & 2 \\
\hline Pulmonary arterioplasty & 1 & 0 & 1 \\
\hline Pulmonary artery band & 1 & 0 & 1 \\
\hline Systemic-to-pulmonary artery shunt & 6 & 1 & 5 \\
\hline \multicolumn{4}{|c|}{ Concomitant cardiac procedures at TAPVC repair } \\
\hline Aortic arch repair & 2 & 1 & 1 \\
\hline Arrhythmia ablation and excision & 1 & 0 & 1 \\
\hline Bidirectional Glenn & 4 & 0 & 4 \\
\hline DORV intraventricular tunnel repair & 1 & 1 & 0 \\
\hline Epicardial pacemaker placement & 1 & 0 & 1 \\
\hline Extracardiac Fontan & 1 & 0 & 1 \\
\hline Mitral and tricuspid valvuloplasty & 1 & 1 & 0 \\
\hline Norwood procedure & 1 & 0 & 1 \\
\hline VSD closure & 1 & 1 & 0 \\
\hline Pulmonary arterioplasty & 9 & 2 & 7 \\
\hline Pulmonary artery banding & 1 & 0 & 1 \\
\hline Pulmonary artery debanding & 1 & 0 & 1 \\
\hline Removal of PV stents & 1 & 0 & 1 \\
\hline Systemic-to-pulmonary artery shunt & 7 & 1 & 6 \\
\hline $\mathrm{CPB}$ time, mean & $95.1 \pm 40.5 \mathrm{~min}$ & $86.2 \pm 31.0 \mathrm{~min}$ & $139.4 \pm 53.3 \mathrm{~min}$ \\
\hline DHCA time, mean & $\begin{array}{c}31.4 \pm 10.7 \mathrm{~min} \\
(\mathrm{n}=38)\end{array}$ & $\begin{array}{c}31.0 \pm 14.6 \mathrm{~min} \\
(\mathrm{n}=27)\end{array}$ & $\begin{array}{c}31.5 \pm 8.8 \mathrm{~min} \\
(\mathrm{n}=11)\end{array}$ \\
\hline Aortic crossclamp time, mean & $42.9 \pm 23.1 \mathrm{~min}$ & $43.9 \pm 22.4 \mathrm{~min}$ & $37.3 \pm 26.8 \mathrm{~min}$ \\
\hline Length of stay, median (range) & $11 \mathrm{~d}(0-281 \mathrm{~d})$ & $11 \mathrm{~d}(0-281 \mathrm{~d})$ & $12 \mathrm{~d}(0-104 \mathrm{~d})$ \\
\hline
\end{tabular}

$B V$, Biventricular; $C P B$, cardiopulmonary bypass; $D H C A$, deep hypothermic circulatory arrest; $D O R V$, double outlet right ventricle; $P D A$, patent ductus arteriosus; $P V$, pulmonary vein; $S V$, single ventricle; $T A P V C$, total anomalous pulmonary venous connection; $V S D$, ventricular septal defect.

a protective effect. Age, gender, preoperative pulmonary venous obstruction, prior systemic to pulmonary artery shunt, aortic crossclamp time, and era of operative repair were not significantly associated with time to mortality. There was no change over time in the frequency of the type of patients repaired (SV vs BV). The clinical course and cause of death in patients with SV anatomy who died are summarized in Table 4.

\section{Reoperation for Pulmonary Venous Stenosis}

Nineteen patients required reoperation for pulmonary venous stenosis (14 in the BV group vs 5 in the $\mathrm{SV}$ group, 
TABLE 2. Association of patient variables with overall mortality

\begin{tabular}{lccc}
\hline \multicolumn{1}{c}{ Variable } & $\begin{array}{c}\boldsymbol{P} \\
\text { value }\end{array}$ & $\begin{array}{c}\text { Hazard } \\
\text { ratio }\end{array}$ & $\begin{array}{c}\mathbf{9 5} \% \\
\text { confidence } \\
\text { interval }\end{array}$ \\
\hline Age & .25 & 0.25 & $0.024-2.60$ \\
Weight* & .028 & 0.55 & $0.32-0.94$ \\
Gender (female) & .35 & 1.51 & $0.64-3.56$ \\
SV* & $<.0001$ & 7.34 & $3.11-17.35$ \\
Heterotaxy* & $<.0001$ & 6.85 & $2.90-16.18$ \\
Pulmonary atresia & .077 & 2.67 & $0.90-7.97$ \\
Mixed-type TAPVC* & .0077 & 3.95 & $1.44-10.85$ \\
Preoperative PV obstruction & .23 & 1.70 & $0.71-4.03$ \\
Prior systemic-to-pulmonary artery shunt & .51 & 1.64 & $0.38-7.03$ \\
CPB time* & .016 & 1.01 & $1.00-1.02$ \\
Aortic crossclamp time & .21 & 1.01 & $0.99-1.03$ \\
Use of DHCA* & .0010 & 6.35 & $2.10-19.16$ \\
Era of repair, compared with present era & & & \\
$\quad$ (2002-2008) & & & \\
1990-1995 & .92 & 0.95 & $0.40-2.46$ \\
1996-2001 & .24 & 0.46 & $0.13-1.66$ \\
\hline
\end{tabular}

$C P B$, Cardiopulmonary bypass; $D H C A$, deep hypothermic circulatory arrest; $P V$, pulmonary vein; $S V$, single ventricle; $T A P V C$, total anomalous pulmonary venous connection. *Statistically significant.

$P=.045)$. There were 23 reoperations; 2 patients underwent 2 reoperations each ( 1 survived, 1 late death), and 1 patient underwent 3 reoperations (survived). The median time to initial reoperation was 104 days (range, 4-753 days). Fifteen of the 19 reoperations $(79 \%)$ occurred within the first 6 months after primary TAPVC repair. Patient variables possibly associated with time to reoperation are summarized in Table 3. Only functional SV anatomy and heterotaxy

TABLE 3. Association of patient variables with reoperation

\begin{tabular}{lccc}
\hline \multicolumn{1}{c}{ Variable } & $\begin{array}{c}\boldsymbol{P} \\
\text { value }\end{array}$ & $\begin{array}{c}\text { Hazard } \\
\text { ratio }\end{array}$ & $\begin{array}{c}\mathbf{9 5} \text { confidence } \\
\text { interval }\end{array}$ \\
\hline Age & .99 & 1.01 & $0.28-3.72$ \\
Weight & 1.00 & 1.00 & $0.76-1.31$ \\
Gender (female) & .12 & 2.07 & $0.83-5.16$ \\
SV* & .045 & 2.86 & $1.02-8.00$ \\
Heterotaxy* & .051 & 2.79 & $1.00-7.82$ \\
Pulmonary atresia & .16 & 2.43 & $0.71-8.36$ \\
Mixed-type TAPVC & .55 & 1.56 & $0.36-6.74$ \\
Preoperative PV obstruction & .48 & 1.40 & $0.55-3.56$ \\
Prior systemic-to-pulmonary artery shunt & .49 & 1.68 & $0.39-7.31$ \\
CPB time & .19 & 1.01 & $1.00-1.02$ \\
Aortic crossclamp time & .94 & 1.00 & $0.98-1.03$ \\
Use of DHCA & .31 & 1.60 & $0.65-3.94$ \\
Era of repair, compared with present era & & & \\
$\quad$ (2002-2008) & & & \\
1990-1995 & .61 & 0.75 & $0.25-2.25$ \\
1996-2001 & .66 & 0.78 & $0.26-2.35$ \\
\hline
\end{tabular}

$C P B$, Cardiopulmonary bypass; $D H C A$, deep hypothermic circulatory arrest; $P V$, pulmonary vein; $S V$, single ventricle; $T A P V C$, total anomalous pulmonary venous connection. *Statistically significant.

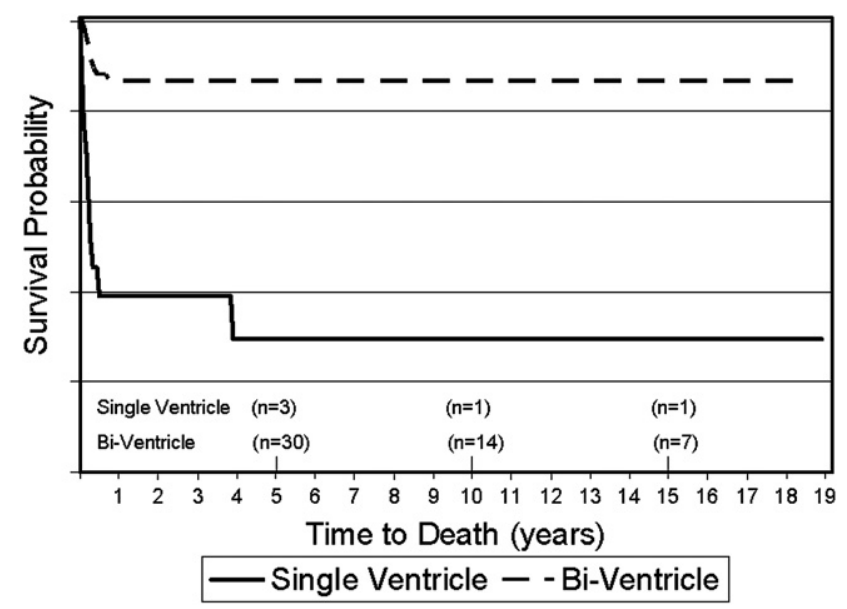

FIGURE 1. Kaplan-Meier curve showing the time to death after initial repair.

syndrome were associated with earlier time to reoperation. Eight patients had PDS for the anastomosis with no reoperations for pulmonary vein stenosis, no operative mortality, and 2 late deaths. Eighty patients had Prolene for the anastomosis with 16 reoperations for pulmonary vein stenosis (much longer follow-up), 9 operative deaths, and 4 late deaths. A comparison of Prolene with PDS showed reoperation $P=.34$, operative mortality $P=1.0$, and late mortality $P=.11$. This seems to come out as mildly in favor of PDS, although it is not statistically significant.

\section{Long-Term Follow-up}

The mean time to follow-up in our series was $4.21 \pm 5.20$ years (range, 1 month to 18.6 years). The mean elapsed time since surgery (maximum possible follow-up) was $7.71 \pm 6.5$ years (range, $0-18.6$ years). Follow-up time was $55 \%$ of the total elapsed time since surgery. Kaplan-Meier curves of SV and BV groups are shown in Figure 1.

Echocardiographic follow-up data were available for 65 patients. Median length of echocardiographic follow-up time was 46 months (range, 1 month to 17.7 years). For 20 of 65 patients, the original study was not available, but a report was available; the mean gradient was reported as unobstructed, mild, moderate, or severe. For these 65 patients the mean gradient was converted to a categoric variable as follows: unobstructed, $<2.5 \mathrm{~mm} \mathrm{Hg}$; mild, $2.5-5 \mathrm{~mm} \mathrm{Hg}$; moderate, $5-10 \mathrm{~mm} \mathrm{Hg}$; severe, $>10 \mathrm{~mm} \mathrm{Hg}$. This resulted in 43 of 65 patients $(66.2 \%)$ classified with no obstruction, 10 of 65 patients $(15.4 \%)$ classified with mild obstruction, 8 of 65 patients $(12.3 \%)$ classified with moderate obstruction, and 4 of 65 patients $(6.2 \%)$ classified with severe obstruction (Figure E4). The patients with severe obstruction either had a reoperation or died of complex medical issues. Of the 45 patients in whom numeric measurements of the mean gradient were available, the median value for the mean gradient was $1.7 \mathrm{~mm} \mathrm{Hg}$ (range, $0.6-15 \mathrm{~mm} \mathrm{Hg}$ ). 
TABLE 4. Mortality in patients with single-ventricle anatomy and total anomalous pulmonary venous connection

\begin{tabular}{|c|c|c|c|c|}
\hline Patient & Diagnosis & Operative repair & Mortality (time since repair) & Cause of death \\
\hline 1 & $\begin{array}{l}\text { 2-day-old male patient with } \\
\text { heterotaxy, pulmonary atresia, } \\
\text { supracardiac TAPVC, } \\
\text { pulmonary coarctation, PDA; } \\
\text { on prostaglandin drip to } \\
\text { maintain PA blood flow, on } \\
\text { ventilator }\end{array}$ & $\begin{array}{l}\text { TAPVC repair, pulmonary } \\
\text { arterioplasty, SP shunt, atrial } \\
\text { septectomy, PDA ligation, } \\
\text { DHCA }\end{array}$ & $\begin{array}{l}\text { Operative }(77 \mathrm{~d}) \text {; } \\
\text { s/p surgical wound drainage } \\
\times 3 \text {; s/p central venous access }\end{array}$ & Sepsis \\
\hline 2 & $\begin{array}{l}\text { 28-day-old female patient with } \\
\text { heterotaxy, unbalanced AVC, } \\
\text { mixed TAPVC, PV } \\
\text { obstruction; on ventilator; } \\
\text { s/p SP shunt }\end{array}$ & TAPVC repair, DHCA & Operative (2 d) & Low cardiac output \\
\hline 3 & $\begin{array}{l}\text { 14-day-old female patient with } \\
\text { heterotaxy, unbalanced AVC, } \\
\text { DORV, pulmonary stenosis, } \\
\text { supracardiac TAPVC, PDA } \\
\text { (on prostaglandin drip), on } \\
\text { ventilator }\end{array}$ & $\begin{array}{l}\text { TAPVC repair, atrial septectomy, } \\
\text { PDA ligation, SP shunt, DHCA }\end{array}$ & $\begin{array}{l}\text { Operative }(32 \mathrm{~d}) ; \\
\text { s/p pericardial drainage, central } \\
\text { venous access; s/p delayed } \\
\text { sternal closure; } \mathrm{s} / \mathrm{p} \\
\text { thrombectomy of SP shunt }\end{array}$ & Low cardiac output \\
\hline 4 & $\begin{array}{l}\text { 1-day-old female patient with } \\
\text { heterotaxy, infracardiac } \\
\text { TAPVC, PV obstruction, PDA; } \\
\text { on ventilator }\end{array}$ & $\begin{array}{l}\text { TAPVC repair, PDA ligation, } \\
\text { central venous access, DHCA }\end{array}$ & $\begin{array}{l}\text { Operative }(71 \mathrm{~d}) \\
\text { s/p delayed sternal closure; } \\
\text { s/p surgical wound drainage } \mathrm{x} 2\end{array}$ & $\begin{array}{l}\text { Sepsis, cardiac tamponade, } \\
\text { ventilator dependent }\end{array}$ \\
\hline 5 & $\begin{array}{l}\text { 12-day-old male patient with } \\
\text { heterotaxy, DORV, mitral } \\
\text { atresia, hypoplastic aortic arch, } \\
\text { supracardiac TAPVC, PV } \\
\text { obstruction, presented in } \\
\text { extremis with pH } 7.1\end{array}$ & $\begin{array}{l}\text { TAPVC repair, atrial septectomy, } \\
\text { PA band, aortic arch repair with } \\
\text { extended end-to-end } \\
\text { anastomosis, DHCA }\end{array}$ & $\begin{array}{l}\text { Operative (died in operating } \\
\text { room) }\end{array}$ & Cardiac failure \\
\hline 6 & $\begin{array}{l}\text { 82-day-old female patient with } \\
\text { heterotaxy, unbalanced AVC, } \\
\text { situs inversus, bilateral SVC, } \\
\text { supracardiac TAPVC, PV } \\
\text { obstruction; s/p PDA ligation, } \\
\text { PA band; on ventilator }\end{array}$ & $\begin{array}{l}\text { TAPVC repair, removal of } 3 \text { stents } \\
\text { retained in atrium, DHCA, TEE }\end{array}$ & $\begin{array}{l}\text { Late }(3.8 \text { y) } \\
\text { s/p bidirectional Glenn, PV } \\
\text { stenosis repair; s/p second PV } \\
\text { stenosis repair, mitral } \\
\text { valvuloplasty, pacemaker }\end{array}$ & $\begin{array}{l}\text { Low cardiac output } \\
\text { Died } 1 \text { mo after second PV } \\
\text { stenosis repair }\end{array}$ \\
\hline 7 & $\begin{array}{l}\text { 35-day-old female patient with } \\
\text { heterotaxy, mitral atresia, } \\
\text { DORV, Scimitar syndrome } \\
\text { (hypoplastic R lung with } \\
\text { systemic arterial supply), COA, } \\
\text { supracardiac TAPVC, PV } \\
\text { obstruction; s/p duodenal } \\
\text { atresia repair }\end{array}$ & $\begin{array}{l}\text { Norwood-Sano procedure, } \\
\text { TAPVC repair, DHCA }\end{array}$ & Operative (2 d) & $\begin{array}{l}\text { Low cardiac output; } \\
\text { postoperative cardiac arrest }\end{array}$ \\
\hline 8 & $\begin{array}{l}\text { 0-day-old female patient with } \\
\text { heterotaxy, pulmonary atresia, } \\
\text { discontinuous PA, supracardiac } \\
\text { TAPVC, PV obstruction, } \\
\text { bilateral PDA, transposition, } \\
\text { common atrioventricular canal; } \\
\text { on ventilator }\end{array}$ & $\begin{array}{c}\text { TAPVC repair, anastomosis of R } \\
\text { and L PA, SP shunt, bilateral } \\
\text { PDA ligation, DHCA }\end{array}$ & $\begin{array}{l}\text { Operative (104 d); } \\
\text { s/p delayed sternal closure; s/p } \\
\text { chest tube for pleural effusion }\end{array}$ & $\begin{array}{l}\text { Multisystem organ failure, } \\
\text { sclerosing venitis, ventilator } \\
\text { dependent }\end{array}$ \\
\hline
\end{tabular}

\section{DISCUSSION}

We reviewed our results with infants undergoing surgical repair of TAPVC at a single institution over a 20-year period. Our experience is somewhat unique in that all patients were operated on by 2 surgeons using virtually identical techniques. The primary surgical strategy was a direct anastomosis between the left atrium and the common pulmonary vein retracting the apex of the heart toward the 
TABLE 4. Continued

\begin{tabular}{|c|c|c|c|c|}
\hline Patient & Diagnosis & Operative repair & Mortality (time since repair) & Cause of death \\
\hline 9 & $\begin{array}{l}\text { 9-day-old female with heterotaxy, } \\
\text { DORV with transposition, situs } \\
\text { inversus, common } \\
\text { atrioventricular valve, } \\
\text { pulmonary stenosis, PDA, } \\
\text { bilateral SVC, supracardiac } \\
\text { TAPVC, atrial tachycardia }\end{array}$ & $\begin{array}{l}\text { TAPVC repair, SP shunt, PDA } \\
\text { ligation, SVT ablation and } \\
\text { excision, DHCA }\end{array}$ & $\begin{array}{l}\text { Late }(157 \mathrm{~d}) \text {; } \\
\text { s/p PA plasty and SP shunt } \times 2 \text {; } \\
\text { s/p PV stenosis repair, mitral } \\
\text { valvuloplasty, bilateral } \\
\text { bidirectional Glenn (operative } \\
\text { mortality) }\end{array}$ & $\begin{array}{l}\text { Low cardiac output, complex } \\
\text { anatomy, recurrent PV stenosi }\end{array}$ \\
\hline 10 & $\begin{array}{l}\text { 3-day-old male patient with } \\
\text { heterotaxy, transposition, } \\
\text { pulmonary atresia, pulmonary } \\
\text { coarctation, atrioventricular } \\
\text { canal, PDA, bilateral SVC, } \\
\text { infracardiac TAPVC, } \\
\text { prematurity }(1.9 \mathrm{~kg})\end{array}$ & $\begin{array}{l}\text { TAPVC repair, SP shunt, } \\
\text { pericardial patch repair of } \\
\text { pulmonary coarctation, DHCA }\end{array}$ & $\begin{array}{l}\text { Operative (died in operating } \\
\text { room) }\end{array}$ & Low cardiac output \\
\hline 11 & $\begin{array}{l}\text { 1-year-old male patient with } \\
\text { unbalanced AVC, mixed } \\
\text { TAPVC; s/p Norwood, s/p SP }\end{array}$ & $\begin{array}{l}\text { TAPVC repair, bidirectional } \\
\text { Glenn }\end{array}$ & $\begin{array}{l}\text { Late }(62 \mathrm{~d}) \\
\text { s/p PV stenosis repair, } \\
\text { bidirectional Glenn }\end{array}$ & $\begin{array}{l}\text { Sudden death at home, family } \\
\text { declined autopsy }\end{array}$ \\
\hline
\end{tabular}

$\overline{A V C}$, Atrioventricular canal; $A V N R T$, atrioventricular nodal reentry tachycardia; $C O A$, coarctation; $D H C A$, deep hypothermic cardiac arrest; $D O R V$, double-outlet right ventricle; $P D A$, patent ductus arteriosus; $P A$, pulmonary artery; $P V$, pulmonary vein; $S P$, systemic-to-pulmonary; $S V C$, superior vena cava; $S V T$, supraventricular tachycardia; $T A P V C$, total anomalous pulmonary venous connection; TEE, transesophageal echocardiogram.

patient's right shoulder. We analyzed these patients to look for risk factors for mortality and reoperation from anastomotic stenosis. We also looked at patient covariables to determine which were associated with adverse outcomes. Our primary findings were that patients with BV anatomy have excellent outcomes and a low incidence of reoperation for anastomotic or pulmonary vein stenosis. In contrast, patients with functional SV anatomy, nearly all of whom in our series also had heterotaxy syndrome (right isomerism), have a significantly increased operative and late mortality and are at increased risk for reoperation from anastomotic stricture and pulmonary vein stenosis. On the basis of the morphology of the anomalous pulmonary venous connection in our series, the mortality was highest for those with a mixedtype connection.

Our analysis focused on comparing the outcomes in patients with BV anatomy versus those with functional SV anatomy. The patients with functional SV ( $94 \%$ heterotaxy) anatomy had late pulmonary vein or anastomotic stenosis in $41 \%$ of the cases. The CPB times were significantly longer in the SV group, and the use of DHCA was nearly twice as common in the patients with functional SV anatomy. Risk factors that were associated with increased mortality included low patient weight, functional SV, heterotaxy syndrome, mixed-type TAPVC, longer CPB time, and use of DHCA. Patients with functional SV anatomy frequently had other associated anomalies, such as pulmonary atresia, pulmonary coarctation, and unbalanced atrioventricular canal defect. These patients all required other procedures and had longer CPB runs and required DHCA. In carefully examining all of the patients with a functional SV and TAPVC, the causes of death seem to be in 2 main categories. Approximately $50 \%$ of those patients died of low cardiac output either in the immediate perioperative period or within the first month after the operation. The other $50 \%$ died of complications of sepsis and multisystem organ failure from prolonged hospitalization and ventilation. These patients with right isomerism (asplenia) are at increased risk for sepsis. It is likely that the difficulty in balancing pulmonary and systemic blood flow in this complex patient group with a systemic single right ventricle was also a significant contributor to the deaths in both groups.

Similar findings were noted in the series from Children's Hospital Boston reported by Hancock Friesen and colleagues. ${ }^{4}$ In that series, $32 \%$ of the patients had SV anatomy. The mortality in the SV group at 36 months was $53 \%$ versus $13 \%$ for the patients with 2 ventricles. That series also concluded that pre-repair pulmonary venous obstruction was a multivariate risk factor for death. In our series, pulmonary vein obstruction was more common in the patients who died, but this did not reach the level of statistical significance. The review by Lodge and associates, ${ }^{9}$ from the Children's Hospital of Philadelphia, reached a similar conclusion regarding patients with functional SV anatomy and TAPVC. Although the early survival of these patients had improved in recent years, the intermediate survival was still $50 \%$. In their series, whether the veins were obstructed or not did not affect early survival. Five of the patients in this series required heart or heart-lung transplantation. In Caldarone and colleagues ${ }^{10}$ review of patients at the Hospital for Sick Children, the mortality for complex cases remained constant at $52 \%$. 
The exception to this is a recent series from Texas Children's Hospital published by Morales and colleagues, ${ }^{11}$ which did show improvement in these complex patients with SV and heterotaxy. Their 5-year survival for patients with heterotaxy was $79 \%$ compared with $89 \%$ for patients without heterotaxy. These results are significantly better than the results reported in our series and others, although they continue to show a $10 \%$ differential between the 2 groups. The majority of their reoperations were also for patients with heterotaxy syndrome. They also found that the rate of pulmonary vein reoperation was statistically greater for patients with heterotaxy than for patients without heterotaxy. By using Cox's proportional hazard model, the authors reported that pulmonary atresia and the need for a systemic pulmonary artery shunt were risk factors for death. In the discussion of that presentation many surgeons noted that these results were dramatically different and better than most reported series. One of the answers addressing this issue was that the Texas Children's Hospital has used a multidisciplinary team to care for patients with heterotaxy syndrome. With these excellent results, some time should be spent evaluating the technical details of their procedure. They limited dissection to the confluence of the pulmonary veins with minimal manipulation of the pulmonary veins. They advocated small endocardial to endothelial bites minimizing the thickness of the anastomosis. They used a technique similar to ours with exposure of the confluence by lifting the apex of the heart toward the right shoulder and creating an extracardiac anastomosis when possible. They preferred to perform the anastomosis under circulatory arrest to optimize visualization and accuracy.

In the majority of patients, we used the technique of elevating the apex of the heart toward the right shoulder, creating an extracardiac anastomosis between the common pulmonary vein and the left atrium. The exception to this was in the patients with coronary sinus TAPVC. For these patients, we used a technique similar to that originally described by van Praagh and associates, ${ }^{12}$ that is, cutting back the coronary sinus, widely opening the atrial septal defect, and performing a pericardial patch closure of the combined orifices of the coronary sinus and the now enlarged atrial septal defect. Our mortality was lowest $(6.7 \%)$ in this group of patients. The highest mortality $(50 \%)$ was observed in the patients with mixed-type TAPVC. The difficulties in patients with mixed TAPVC were reported by Delius and colleagues ${ }^{13}$ from Great Ormond Street. The recent review by Chowdhury and associates ${ }^{14}$ from the All India Institute revealed that the risk of death was 5.8 times higher in patients with category III of mixed TAPVC.

One of the issues recently raised in the surgical literature is whether or not the vertical vein should be ligated at the time of total anomalous pulmonary venous repair. Chowdhury and colleagues ${ }^{15}$ noted a higher operative mortality in patients who had their vertical vein ligated. They recommended the use of an adjustable ligature around the vertical vein in patients with more than moderate post-bypass pulmonary hypertension. Their article was the subject of an editorial by Dr Tweddell, who questioned this strategy. ${ }^{16}$ We ligated the vertical vein in all of our patients and were able to manage their postoperative pulmonary hypertension with nitric oxide therapy and conventional ventilator management strategies.

Our technique was associated with approximately $20 \%$ of the patients requiring reoperation for pulmonary vein stenosis. Reoperation for pulmonary vein or anastomotic stenosis was more common in the patients with a functional SV than those with BV anatomy. Most of these reoperations occurred within 6 months of surgery. The primary technique used to repair the patients with pulmonary vein stenosis was the sutureless technique, previously described by Caldarone and colleagues ${ }^{17}$ and Lacour-Gayet and colleagues. ${ }^{18}$ In evaluating patient variables that were risk factors for reoperation, the only statistically significant associations were functional SV and heterotaxy syndrome. We were somewhat disappointed that the era of repair did not result in an improvement in the reoperation rate for anastomotic stenosis. The distribution of patients with more complex SV anatomy was constant during the study period and did not factor into any significant era effects. Hawkins and associates ${ }^{19}$ previously reported that the use of an absorbable suture was associated with a reduced incidence of anastomotic stenosis. Although we did not have enough patients with absorbable suture $(\mathrm{n}=8)$ to make a definitive comparison, our results are mildly in favor of the use of an absorbable suture such as PDS.

The majority of the patients who have had long-term follow-up echocardiograms have a low gradient at the pulmonary vein anastomosis. The median value for the gradient at the anastomosis was $1.7 \mathrm{~mm} \mathrm{Hg}$, with a median followup of 46 months. Because significant restenosis requiring reoperation occurred within 6 months of surgery in the majority of patients, we believe that a 46-month follow-up time is acceptable to demonstrate good intermediate-term results.

\section{CONCLUSIONS}

The outcomes of patients with TAPVC seem to have a dichotomous distribution. The patients with BV anatomy, no associated significant cardiac anomalies, and unobstructed pulmonary veins have a low operative mortality and excellent long-term outcome with a low incidence of anastomotic or pulmonary vein stenosis using the technique we have described. However, in patients with functional SV anatomy, nearly all had associated heterotaxy syndrome (right atrial isomerism, asplenia), a high operative and late mortality, and a high incidence of reoperation for anastomotic or pulmonary vein stenosis. For these patients with heterotaxy syndrome with SV physiology, we must focus on more careful balancing of the pulmonary and systemic circulation and careful avoidance of postoperative bloodstream and other 
infections. In these patients, there is little margin for error regarding either of these 2 issues given their overall marginal cardiac output. There is clearly room for improvement in our management strategies for this patient population. Unfortunately, it does seem that patients with a combination of right atrial isomerism with a functional SV and obstruction of the anomalous pulmonary veins with the potential for sepsis, given the associated asplenia, are a formidable and challenging group.

\section{References}

1. Kirshbom PM, Myung RJ, Gaynor JW, Ittenbach RF, Paridon SM, DeCampli WM, et al. Preoperative pulmonary venous obstruction affects longterm outcome for survivors of total anomalous pulmonary venous connection repair. Ann Thorac Surg. 2002;74:1616-20.

2. Karamlou T, Gurofsky R, Al Sukhni E, Coles JG, Williams WG, Caldarone CA, et al. Factors associated with mortality and reoperation in 377 children with total anomalous pulmonary venous connection. Circulation. 2007;115:1591-8.

3. Burroughs JT, Edwards JE. Total anomalous pulmonary venous connection. Am Heart J. 1960;59:913-31.

4. Hancock Friesen CL, Zurakowski D, Thiagarajan RR, Forbess JM, del Nido PJ, Mayer JE, et al. Total anomalous pulmonary venous connection: an analysis of current management strategies in a single institution. Ann Thorac Surg. 2005; 79:596-606

5. Morales DL, Braud BE, Booth JH, Graves DE, Heinle JS, McKenzie ED, et al. Heterotaxy patients with total anomalous pulmonary venous return: improving surgical results. Ann Thorac Surg. 2006;82:1621-7.

6. Tanel RE, Kirshbom PM, Paridon SM, Hartman DM, Burnham NB, McBride MG, et al. Long-term noninvasive arrhythmia assessment after total anomalous pulmonary venous connection repair. Am Heart J. 2008;153:267-74.

7. Herlong JR, Jaggers JJ, Ungerleider RM. Congenital Heart Surgery Nomenclature and Database Project: pulmonary venous anomalies. Ann Thorac Surg. 2000;69(4 Suppl):S56-69.
8. Jacobs JP, Mavroudis C, Jacobs ML, Joint EACTS-STS Congenital Database Committee. What is operative mortality? Defining death in a surgical registry database: a report of the STS Congenital Database Taskforce and the Joint EACTS-STS Congenital Database Committee. Ann Thorac Surg. 2006;81: 1937-41.

9. Lodge AJ, Rychik J, Nicolson SC, Ittenbach RF, Spray TL, Gaynor JW. Improving outcomes in functional single ventricle and total anomalous pulmonary venous connection. Ann Thorac Surg. 2004;78:1688-95.

10. Caldarone CA, Najm HK, Kadletz M, Smallhorn JF, Freedom RM, Williams WG, et al. Surgical management of total anomalous pulmonary venous drainage: impact of coexisting cardiac anomalies. Ann Thorac Surg. 1998;66:1521-6.

11. Morales DL, Braud BE, Booth JH, Graves DE, Heinle JS, McKenzie ED, et al. Heterotaxy patients with total anomalous pulmonary venous return: improving surgical results. Ann Thorac Surg. 2006;82:1621-7.

12. van Praagh R, Harken AH, Delisle G, Ando M, Gross RE. Total anomalous pulmonary venous drainage to the coronary sinus. A revised procedure for its correction. J Thorac Cardiovasc Surg. 1972;64:132-5.

13. Delius RE, de Leval MR, Elliott MJ, Stark J. Mixed total pulmonary venous drainage: still a surgical challenge. J Thorac Cardiovasc Surg. 1996;112:1581-8.

14. Chowdhury UK, Airan B, Malhotra A, et al. Mixed total anomalous pulmonary venous connection: anatomic variations, surgical approach, techniques, and results. J Thorac Cardiovasc Surg. 2008;135:106-16.

15. Chowdhury UK, Subramaniam KG, Joshi K, Varshney S, Kumar G, Singh R, et al. Rechanneling of total anomalous pulmonary venous connection with or without vertical vein ligation: results and guidelines for candidate selection. J Thorac Cardiovasc Surg. 2007;133:1286-94.

16. Tweddell JS. The vertical vein: to ligate or not to ligate. J Thorac Cardiovasc Surg. 2007;133:1135-6.

17. Caldarone CA, Najm HK, Kadletz M, Smallhorn JF, Freedom RM, Williams WG, et al. Relentless pulmonary vein stenosis after repair of total anomalous pulmonary venous drainage. Ann Thorac Surg. 1998;66:1514-20.

18. Lacour-Gayet F, Rey C, Planche C. Pulmonary vein stenosis: description of a sutureless surgical technique using the pericardium in situ. Arch Mal Coeur Vaiss. 1996;89:633-6

19. Hawkins JA, Minich LL, Tani LY, Ruttenberg HD, Sturtevant JE, McGough EC. Absorbable polydioxanone suture and results in total anomalous pulmonary venous connection. Ann Thorac Surg. 1995;60:55-9. 


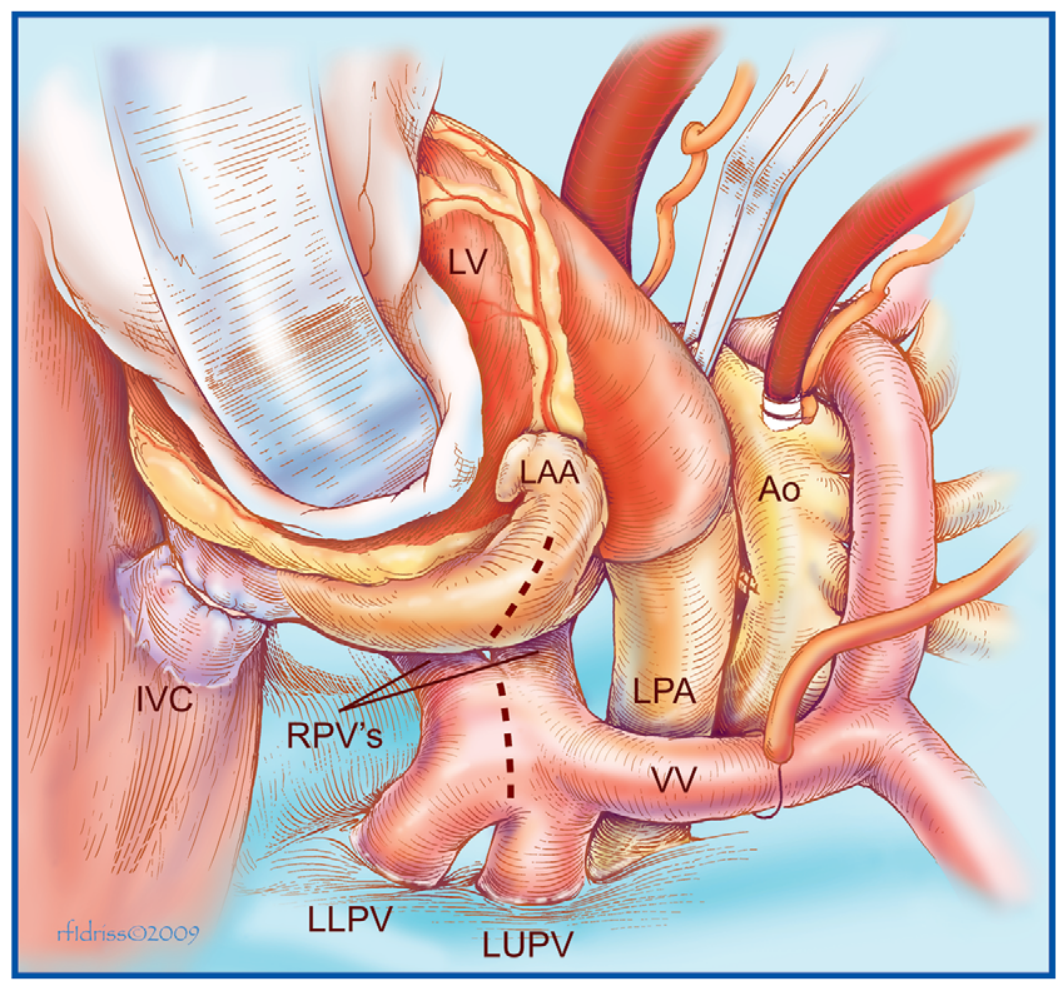

FIGURE E1. Patient who has supracardiac TAPVC and is on CPB with bicaval venous cannulation. The aorta has been crossclamped, and cold blood cardioplegia has been delivered. The surgeon is standing on the left side of the table, and the assistant is retracting the apex of the heart toward the right shoulder of the patient. The inferior vena cava and superior vena cava have been snared. The dotted lines indicate the 2 incisions to be made: 1 in the left atrium and 1 in the common pulmonary vein. There is a snare around the vertical vein that is superior to the left pulmonary artery. The vertical vein is ligated just before opening the common pulmonary vein. Reprinted with permission: Mavroudis C, Backer CL, eds. Pediatric Cardiac Surgery. 3rd ed. Philadelphia, PA: Mosby, Inc; 2003. $L V$, Left ventricle; $L A A$, left atrial appendage; $A o$, aorta; $L P A$, left pulmonary artery; $V V$, vertical vein; $I V C$, inferior vena cava; $R P V$, right pulmonary vein; $L L P V$, left lower pulmonary vein; $L U P V$, left upper pulmonary vein. 


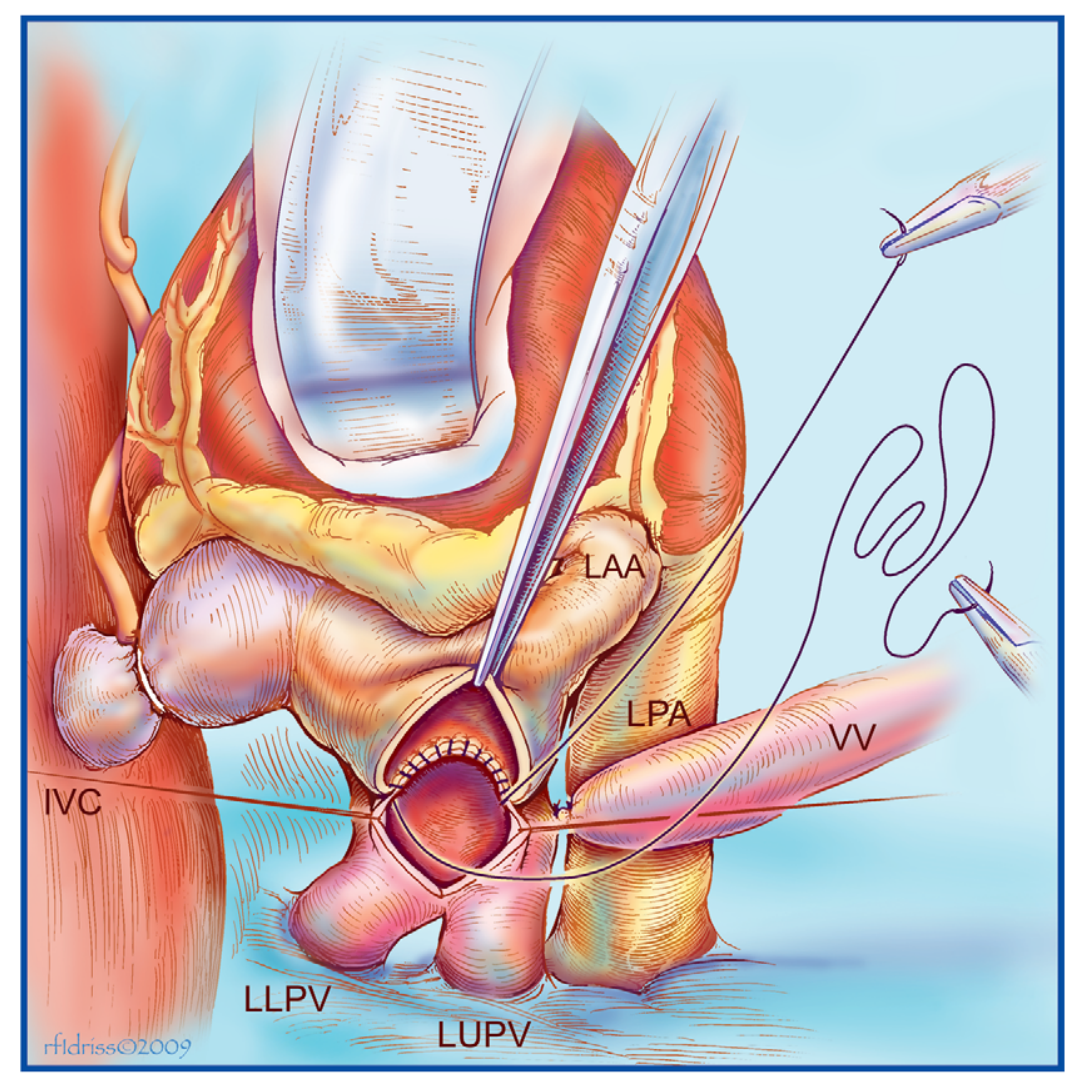

FIGURE E2. An anastomosis performed in a parachute-type fashion between the left atrium and the common pulmonary vein. In most patients, a widely patent anastomosis such as this can be achieved. Note that the incision in the common pulmonary vein does not extend into the branches of the pulmonary veins themselves. The vertical vein has been ligated. Reprinted with permission: Mavroudis C, Backer CL, eds. Pediatric Cardiac Surgery. 3rd ed. Mosby, Inc; 2003. $L A A$, Left atrial appendage; $L P A$, left pulmonary artery; $V V$, vertical vein; $I V C$, inferior vena cava; $L L P V$, left lower pulmonary vein; $L U P V$, left upper pulmonary vein.

\section{Ventricular Anatomy and Need for Reoperation}

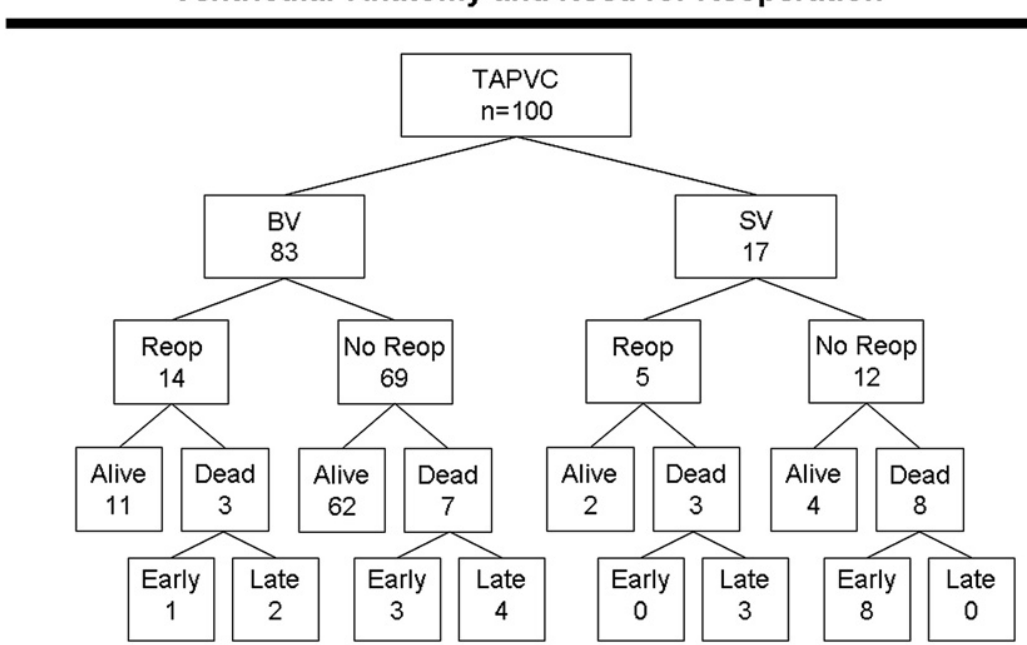

Early and Late Deaths defined in relation to primary TAPVC repair

FIGURE E3. Flow tree summarizes the outcomes of patients with BV and functional SV anatomy. TAPVC, Total anomalous pulmonary venous connection; $B V$, biventricular; $S V$, single ventricle. 


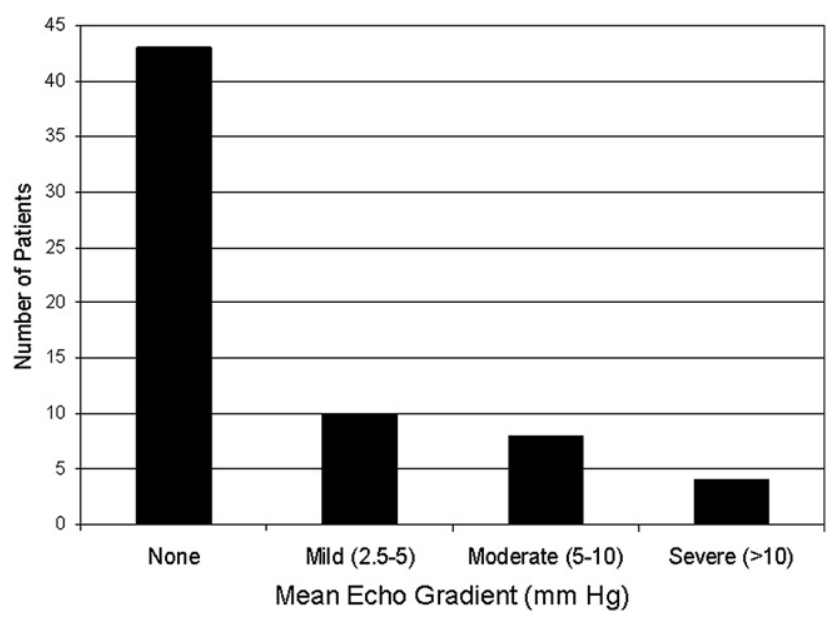

FIGURE E4. Chart showing the gradient at pulmonary vein anastomosis. 